\title{
Improving Heat Transfer from Peltier Devices Used in an Atmospheric Water Generation
}

\author{
Mark Summers and Bahram Asiabanpour
}

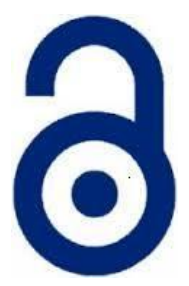

Received: 28 February 2021

Accepted: 29 April 2021

Published: 15 July 2021

Publisher: Deer Hill Publications

(C) 2021 The Author(s)

Creative Commons: CC BY 4.0

\begin{abstract}
Present Atmospheric Water Generation (AWG) systems are useful for providing water in areas with limited water supplies. Many industrial AWG systems use VCR (vapor-compression refrigeration) to achieve a large amount of cooling to extract liquid water out of the air. These systems require large amounts of energy to operate, usually in the form of diesel or AC-powered generators. The systems also have many moving parts that require maintenance and use refrigerants that can leak and cause problems with the environment. An alternative AWG solution is to use DC-powered Peltier devices (thermoelectric coolers) to reduce the temperature of condensation plates to extract water from the air. This solution eliminates the issues with traditional industrial AWG systems since the Peltier devices are solid-state, have very long mean-time between failure (MTBF) performance, and can be powered by solar panels that eliminate the need to burn hydrocarbon-based fuels or have access to a reliable power grid. Also eliminated is the need to use chlorofluorocarbon (CFC) or hydrochlorofluorocarbons (HCFC) refrigerants that have been shown to deplete the ozone layer. This paper will present methods to improve the efficiency of the thermoelectric coolers by more efficiently extracting heat from the hot side of the device. This efficiency will be quantified by evaluating the coefficient of performance (COP) of the thermoelectric cooler under the various operating conditions. Different combinations of conductive heat transfer using aluminium heatsinks, convection heat transfer using forced airflow, and phase change heat transfer using copper heat pipes filled with distilled water will be investigated and evaluated. Keywords: AWG, Atmospheric Water Generation, thermoelectric coolers, Simulation, Modelling, Optimization
\end{abstract}

\section{INTRODUCTION}

Meeting the growing water demand is proving to be one of the most critical challenges of the century [1]. The African Wildlife Foundation estimates that people need 20 to 50 litres of clean water daily to meet their basic needs and in emerging economies, women spend 40 billion work hours each year walking to collect freshwater [2]. Even in developed countries, the increased industrial and agricultural use of water that often comes from freshwater sources has created an urgent demand for other sources of freshwater [3]. Unfortunately, the naturally occurring freshwater sources are not replenished at a rate to match the growing demand. The need for water also comes with a high energy demand, which, in turn, comes with its water demand. The water demand cannot be studied or met without also considering the resulting energy demand. Energy is required to pump, heat, treat and cool and deliver water [4]. Many options exist to help increase the supply of water to these areas in need. Desalination of seawater, the building of aqueducts to transport water from areas with more abundant water supplies, and over-the-road transport of water from one region to another are all possible options, but require infrastructure that might not be in place. Other options include commercial atmospheric water generation (AWG) systems, but these require an infrastructure of reliable power to make it happen.

Current commercially available AWG systems from companies like Innovaqua Water Solutions, Quality Water Treatment, and Atmospheric Water Solutions have products that can produce water, but have two major drawbacks that we want to address in this research:

- $\quad$ Requirements for uninterrupted reliable access to grid power.

- Lack of intelligence to determine operating schedule to ensure maximum utilization of available power.

Since our target audience has neither reliable access to power, nor the ability to efficiently determine when to operate the system, our system is focused on optimization to know when to operate the system based on local

M. Summers and B. Asiabanpour $区$

Ingram School of Engineering- Texas State University

San Marcos, TX 78666 USA

E-mail: ba13@txtstate.edu

Reference: Summers and Asiabanpour (2021). Improving Heat Transfer from Peltier Devices Used in an Atmospheric Water Generation. International Journal of Engineering Materials and Manufacture, 6(3), 170-175. 
atmospheric conditions (dry bulb temperature and relative humidity) and available power (current $\mathrm{kW}$-hr capacity and the forecast for near-term solar generation).

\section{AWG SYSTEM DESCRIPTION}

Atmospheric Water Generation (AWG) offers a sustainable option to secure freshwater for years to come [5]. AWG is expected to be an $\$ 8$ billion market by 2024 [6]. AWG is the process of removing and collecting water vapor from the air. Condensation forms when air at the saturation temperature comes in contact with a surface that is below this saturation temperature [7]. AWG systems cool a surface and then pass air over it, allowing the moisture to be extracted from the air as it passes [8-9].

AWG systems can rely on a wide array of cooling techniques. Standard systems use refrigerant-based dehumidification, vapor compression, and vapor absorption refrigeration or desiccant liquid. Recently, other methods such as Thermo-electric cooling and heat exchange using lower ground temperatures have been studied [10]. All of these cooling techniques that make AWG possible require power. Current AWG systems require a minimum of $6.8 \mathrm{~g} / \mathrm{m} 3$ water vapor density and operate ideally at the World Standard Conditions of $26.7^{\circ} \mathrm{C}$ and $60 \% \mathrm{RH}$ to operate at an efficiency of $0.4 \mathrm{kWh} / \mathrm{L}$ [11]. In the meantime, the economic aspects of the AWG systems and the feasibility of their usage compared to other sources of freshwater have been studied [12-14]. The techniques and methods that improve the efficiency of such AWG systems in produce more water with less energy is an area of interest for scaling these methods from laboratory scale to commercial and widespread use.

One of the methods of AWG systems is to use DC-powered Peltier devices (thermoelectric coolers) (Fig. 1) to reduce the temperature of condensation plates to extract water from the air. This solution eliminates the issues with traditional industrial AWG systems since the Peltier devices are solid-state, have very long mean-time between failure (MTBF) performance, and can be powered by solar panels that eliminate the need to burn hydrocarbon-based fuels or have access to a reliable power grid. Also eliminated is the need to use chlorofluorocarbon (CFC) or hydrochlorofluorocarbons (HCFC) refrigerants that have been shown to deplete the ozone layer. However, thermoelectric coolers have relatively low efficiency. Vapor-Compression Refrigeration (VCR) systems as used in many residential and commercial buildings offer much better efficiency. However, they have many moving parts (not solid-state), have lower MTBF, and require reliable sources of alternating current. They also require refrigerants that have been proven to cause damage to the earth's atmosphere. Additionally, the thermoelectric cooler device operates on the Peltier effect. The device can accept DC as input and produce a delta temperature as an output (Peltier), or can accept a temperature difference as input and produce a DC as output.

A major challenge with Peltier devices is providing adequate cooling to the hot side of the device. The device can only produce a temperature difference $(\Delta T)$. The idea is to attach a condensation plate to the cold side to condense atmospheric water out of the available air to produce water. To minimize the power needed, the challenge is to remove heat from the hot side in an efficient manner to maximize water generated per watt-hour energy expended.

This paper will present methods to improve the efficiency of the thermoelectric coolers by more efficiently extracting heat from the hot side of the device. The rest of this paper is organized as the following. In section 3 , method and materials including modelling and manufacturing are presented. Section 3 illustrates the results including the simulation model and fabricated test system. Conclusions and discussions are presented in Section 4.

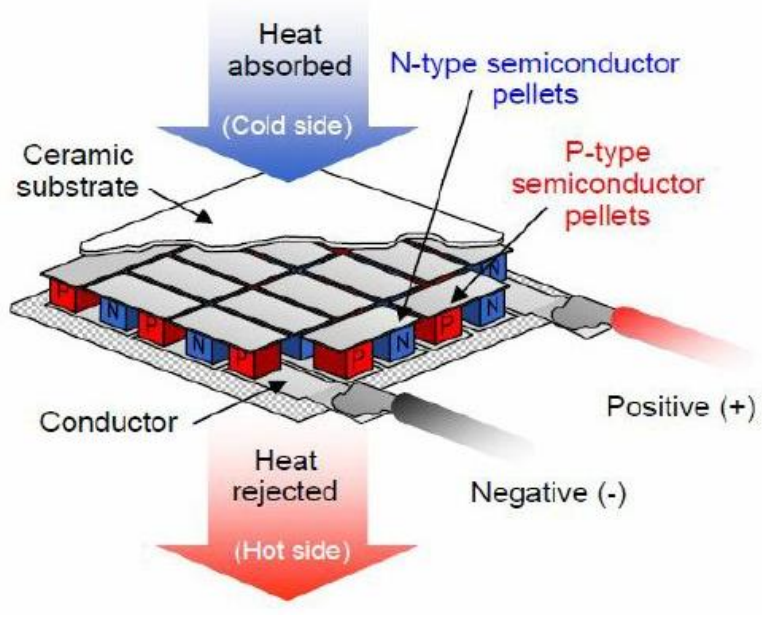

Figure 1: The semiconductor thermoelectric cooler with hot and cold sides [15] 


\section{METHODS AND MATERIALS}

Laws of nature constrain us to the fact that heat will naturally move from hot objects to cold objects. Physics provides us with four basic methods to move heat in the opposite direction: Convection (solid material as a medium), Conduction (gas/fluid as a medium), Radiation (via electro-magnetic radiation), and Phase Change (solid-to-liquidto-gas).

This work has employed all but radiation techniques to systematically determine the best combination to optimize the temperature reduction of the hot side of the Peltier devices. The approaches used are as follows.

- Convection: Round aluminium finned heat sinks of various lengths.

- Conduction: DC tube axial fans blow air across these heat sinks.

- Phase Change: Copper wicked heat pipes with distilled water under vacuum.

An initial AWC testbed including a platform with (4) single commercial $40 \mathrm{~mm} \times 40 \mathrm{~mm}$ TEC assemblies cooled with rectangular aluminium heat sinks (conduction) and DC fans (convection) and the system was tested for its efficiency (Fig. 2). The results illustrated that the heatsink mechanism is not efficient enough and the system is not getting cold enough in an energy-efficient fashion to produce water economically. Since the Peltier devices can only generate a temperature difference between the hot and cold side of the device, when the hot side is not cooled in an efficient manner, the temperature of the cold side rises as well, which causes reduced condensation and also causes the Pelter device to operate at a lower COP (Fig 3).

As a result of this initial testing, two new approaches were implemented.

a) Increase surface area of the condensation plates.

b) Improve heat transfer away from the hot side of the TEC.

To improve the system, parallel modelling/simulation and Fabrication/Experimentation approaches were pursued to optimize the system. This study focuses solely on the Modelling and Simulation aspects of the work.

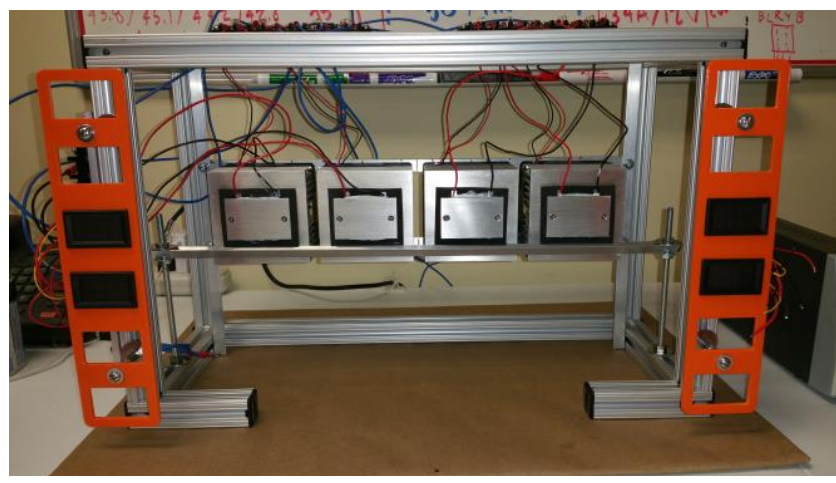

Figure 2: Original 4 TEC Platform

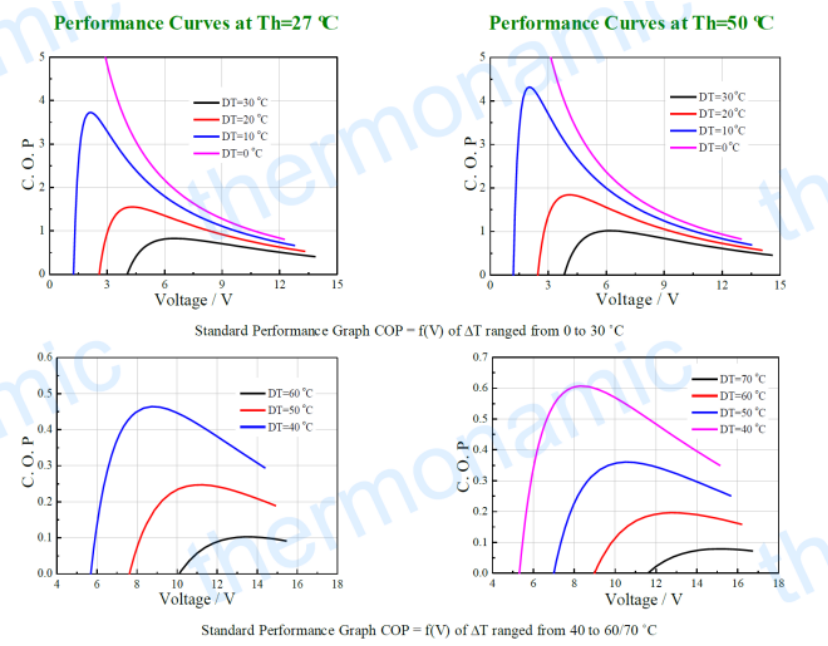

Figure 3: TEC Coefficient of Performance 


\subsection{Modelling and Simulation}

Solidworks software was used to develop a manufacturing computer model of the system (Fig.4) including the TEC, heatsink, fans, and other mechanical structures. Additionally, Solidworks built-in Flow Simulation was used to implement Computation Fluid Dynamics (CFD) modelling.

This new improved test platform was about double the size of the original test platform. It contains (4) 8-1/2" $x$ $8-1 / 2$ " $\times 1 / 8$ " aluminium condensation plates, (4) $235 \mathrm{cfm}$ cooling fans, and varying arrangements of one, two three, and four TEC configurations. Also added were spiral ducted air plenums to more efficiently direct the airflow over the new round heat sinks. Four different configurations of heat sink/heat pipe assemblies were designed and manufactured to test the hypothesis of using various combinations of multiple heat transfer mechanisms to optimize the water generation results (Fig. 5).

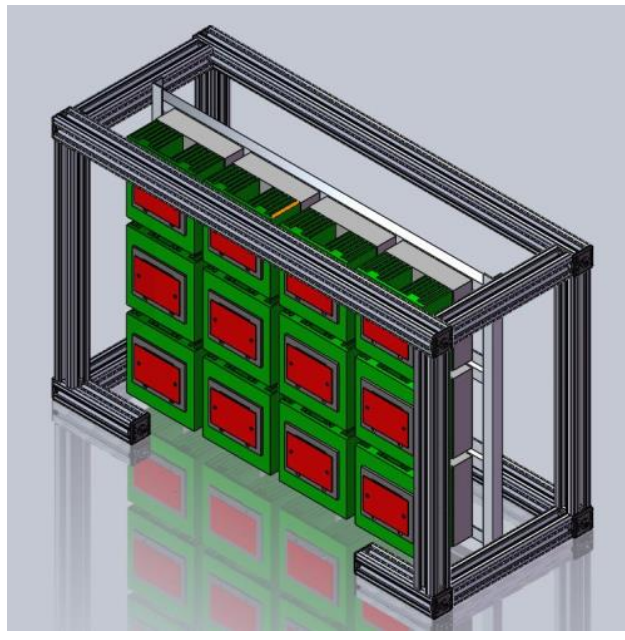

Figure 4: Original 4 TEC Platform

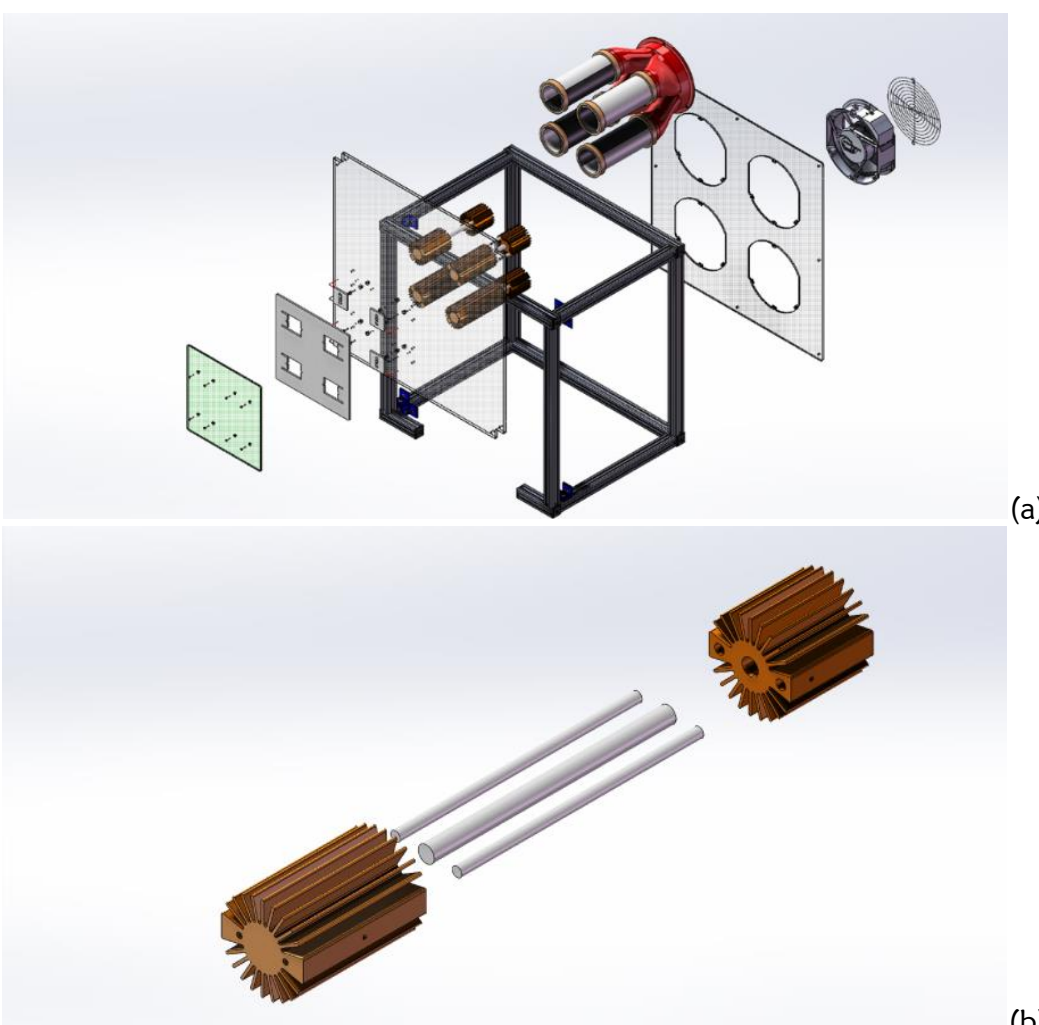

(b)

Figure 5: AWG Test Platform with Configurable Condensation Plate Assemblies (a) and Hybrid Heat Sink / Heat Pipe Cooling Assembly (b) 


\section{RESULTS}

The improved AWG Test Platform proved to be much better than the original. The individually configurable condensation plates will allow multiple arrangements of TECs and consistent test results. The CFD analysis was done closely matches the actual hardware temperature performance, which will allow for much quicker "what-if" simulations without building additional hardware (Fig. 6).

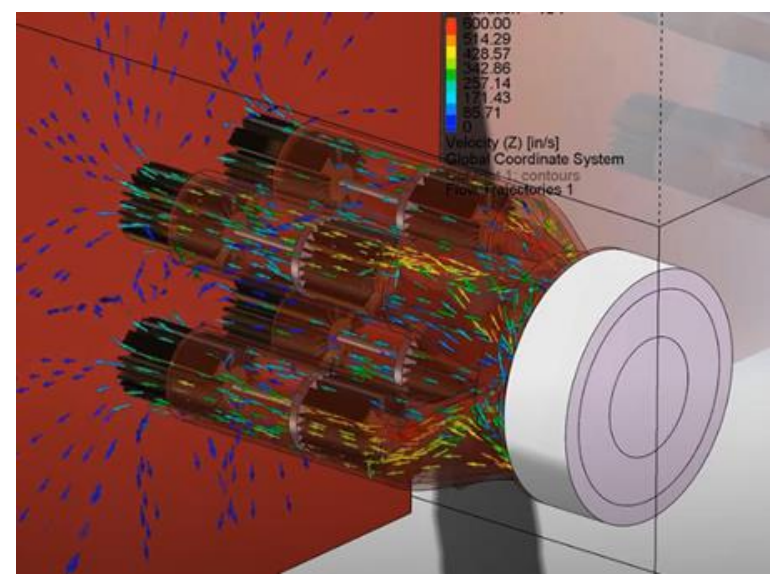

Figure 6: Computation Fluid Dynamics (CFD) Simulation of Four-Way Duct Design

The approach that was used regarding mesh sensitivity was different than our earlier efforts. Initially, multiple simulations were run at various mesh sizes and configurations to see if we could identify locations of the simulation that produced different results based on the mesh size. This proved to be a very time-consuming process. Therefore, instead we chose to use an initial default mesh and compared the simulation results to measurements from the instrumented hardware. We implemented Vernier temperature probes and air flow meters to make these measurements. When the simulation results deviated significantly from the measured results, a finer local mesh in these regions was applied until a satisfactory correlation was achieved. Adding the heat pipes offered marginal benefits on the initial testing. However, additional configurations are using larger diameter heat pipes that still need to be manufactured and tested. Bluetooth temperature sensors allow temperature probing of the surface of the heatsinks, hot and cold sides of the TECs, and airflow temperature. Airflow sensors allow validation of the results of the CFD analysis, which further strengthens the ability to perform "what-if" design changes to the duct geometry for design iteration improvements without the need for time-consuming and costly fabrication of intermediate design improvements.

\section{CONCLUSION AND DISCUSSIONS}

CFD Simulation and validation results were very close to actual measured values. To quantify these correlations, we utilized a FLIR C2 thermal camera to capture the transient temperature profile of the four-TEC condensation plate configuration [Fig. 7] and correlated it the steady-state results of the associated Solidworks Flow Simulation results. This validation model will facilitate a wide range of design of experiments tests and optimizations without the need to fabricate physical models.

Due to the scalable design of the AWG test platform, once the initial design achieves an adequate level of optimization, multiple copies of the test platform can be manufactured into a unit suitable for field tests. A separate optimized solar panel system is also being designed and tested for potential use as a power source for the AWG system.

The Peltier devices are still operating at a sub-optimal coefficient of performance (COP). Ideas for increase optimization include heat sinks with a higher number of thinner fins, investigation of additional TEC arrangements (new spacings and quantities), incorporation of computer-controlled power inputs based on local atmospheric conditions (dry-bulb temperature, atmospheric pressure, and relative humidity). 


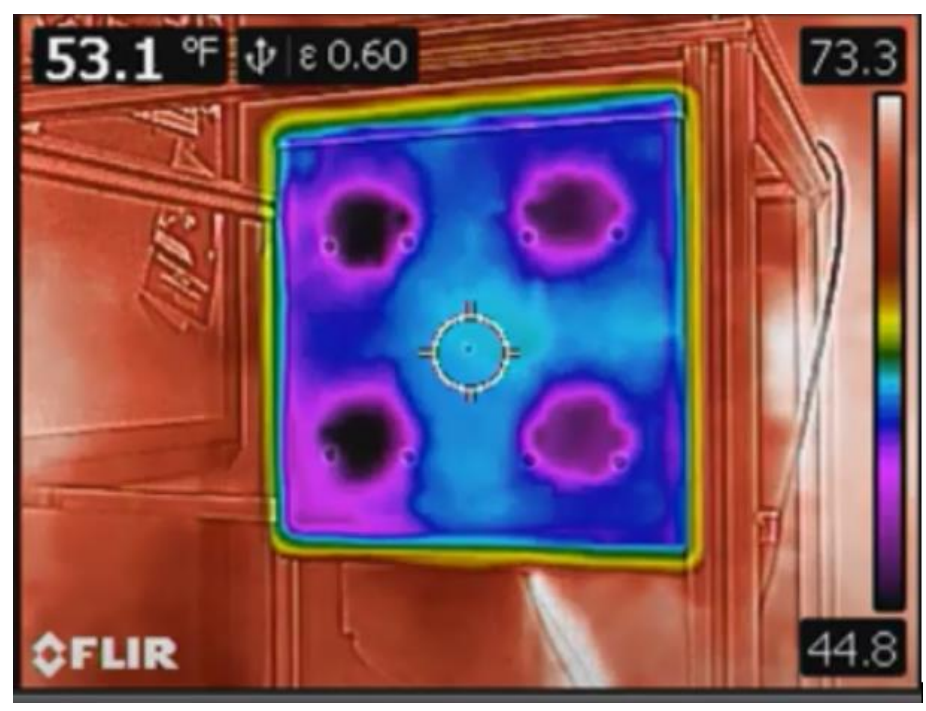

Figure 7: The transient temperature profile of the four-TEC condensation plate configuration by thermal camera

\section{ACKNOWLEDGEMENT}

This work was completed with funding from the US Department of Agriculture (Grant \# 2016-38422-25540). The authors would like to thank the USDA and Texas State University for providing funding and access to both infrastructure and laboratories. The sponsors are not responsible for the content and accuracy of this article. The authors declare that there is no conflict of interest regarding the publication of this paper.

\section{REFERENCE}

1. Postel, Sandra L. "Entering an Era of Water Scarcity: The Challenges Ahead." Ecological Applications, vol. 10, no. 4, 2000, pp. 941-948. JSTOR, JSTOR, www.jstor.org/stable/2641009.

2. Weil, Sydney. "How Does Water Use in the United States Compare to That in Africa?" African Wildlife Foundation, 6 Sept. 2013, www.awf.org/blog/how-does-water-use-united-states-compare-africa.

3. Wilson, Lynn. "The Costs of Fresh Water in a Changing World (Op-Ed)." Livescience, Purch, 22 Apr. 2014, www.livescience.com/45049-costs-of-fresh-water.html.

4. "Ensuring the Resiliency of Our Future Water and Energy Systems." Department of Energy, 2014, www.energy.gov/articles/ensuring-resiliency-our-future-water-and-energy-systems.

5. Adeoye, O.O., et al. “Atmospheric Water Generation: A Path to Net-Zero." 2016 IEEE Green Technologies Conference (GreenTech), 2016, doi:10.1109/greentech.2016.16.

6. "Atmospheric Water Generator Market - US\$8 Billion revenue by 2024." PR Newswire, 15 Nov. 2017.

7. Esfahani, J.A., Modirkhazeni, S.M. 2012. “Modeling of Laminar, Film-Wise Condensation." In Ahsan, Amimul, Water Condensation: Process, Modeling and Control, pp 1-70. Nova Science Publishers Inc., New York.

8. Almusaied, Z., Asiabanpour, B. Atmospheric Water Generation: Technologies and Influential Factors.". Institute of Industrial and Systems Engineers Research Conference 2017, PA, 2017.

9. Ownby, N., and Asiabanpour, B. "Reduction of Power Consumption in Atmospheric Water Generation", 9th International Conference of Environmental Science and Technology, Houston, TX, 2018.

10. Pontious, K., Weidner, B. Guerin, N. Dates, A. Pierrakos, O., and Altaii, K., "Design of an atmospheric water generator: Harvesting water out of thin air," 2016 IEEE Systems and Information Engineering Design Symposium (SIEDS), Charlottesville, VA, 2016, pp. 6-11. doi: 10.1109/SIEDS.2016.7489327

11. Wahlgren, Ronald V. 2016. "Water-from-Air Quick Guide: Second Edition”. Atmoswater Research, North Vancouver, BC.

12. Asiabanpour, B., Ownby, N., Summers, M., Moghimi, F. (2019), "Atmospheric water generation and energy consumption: an empirical analysis", IEEE Texas power and energy conference (TPEC), 1-6

13. Moghimi, F., Ghoddusi, H., Asiabanpour, B., Behroozikhah, M. (2019), "Atmospheric water generation (awg): performance model and economic analysis", IFIP International Conference on Advances in Production Management Systems

14. Moghimi, F., Ghoddusi, H., Asiabanpour, B., Behroozikhah, M. (2021), "Is atmospheric water generation an economically viable solution?", Clean Technologies and Environmental Policy, 1-18.

15. Parinov, I. and Shun-Hsyung-Chang (2013), "Research Opportunity To Use MISM Structures For Cooling Of Light-Emitting Diodes", Edition: Nova Publisher: Nova Science Publishers, Inc, ISBN: $978-1-62618-535-$ 7, DOI: 10.13140/RG.2.1.4082.4162 